\title{
Rapid meridional transport of tropical airmasses to the Arctic during the major stratospheric warming in January 2003
}

\author{
A. Kleinböhl ${ }^{1, *}$, J. Kuttippurath ${ }^{1}$, M. Sinnhuber ${ }^{1}$, B.-M. Sinnhuber ${ }^{1}$, H. Küllmann ${ }^{1}$, K. Künzi ${ }^{1}$, and J. Notholt ${ }^{1}$ \\ ${ }^{1}$ Institute of Environmental Physics, University of Bremen, Bremen, Germany \\ "now at: Jet Propulsion Laboratory, Pasadena, CA, USA
}

Received: 2 April 2004 - Published in Atmos. Chem. Phys. Discuss.: 3 November 2004

Revised: 3 March 2005 - Accepted: 9 April 2005 - Published: 1 June 2005

\begin{abstract}
We present observations of unusually high values of ozone and $\mathrm{N}_{2} \mathrm{O}$ in the middle stratosphere that were observed by the airborne submillimeter radiometer ASUR in the Arctic. The observations took place in the meteorological situation of a major stratospheric warming that occurred in mid-January 2003 and was dominated by a wave 2 event. On 23 January 2003 the observed $\mathrm{N}_{2} \mathrm{O}$ and $\mathrm{O}_{3}$ mixing ratios around $69^{\circ} \mathrm{N}$ in the middle stratosphere reached maximum values of $\sim 190 \mathrm{ppb}$ and $\sim 10 \mathrm{ppm}$, respectively. The similarities of these $\mathrm{N}_{2} \mathrm{O}$ profiles in a potential temperature range between 800 and $1200 \mathrm{~K}$ with $\mathrm{N}_{2} \mathrm{O}$ observations around $20^{\circ} \mathrm{N}$ on 1 March 2003 by the same instrument suggest that the observed Arctic airmasses were transported from the tropics quasi-isentropically. This is confirmed by 5 -day back trajectory calculations which indicate that the airmasses between about 800 and $1000 \mathrm{~K}$ had been located around $20^{\circ} \mathrm{N} \mathrm{3-5}$ days prior to the measurement in the Arctic. Calculations with a linearized ozone chemistry model along calculated as well as idealized trajectories, initialized with the low-latitude ASUR ozone measurements, give reasonable agreement with the Arctic ozone measurement by ASUR. PV distributions suggest that these airmasses did not stay confined in the Arctic region which makes it unlikely that this dynamical situation lead to the formation of dynamically caused pockets of low ozone.
\end{abstract}

\section{Introduction}

Stratospheric warmings are a common feature in the Arctic stratosphere (e.g. Andrews et al., 1987), and have also been found in the Antarctic stratosphere, recently in connection with a split of the Antarctic ozone hole in Southern hemisphere winter 2002 (e.g. Sinnhuber et al., 2003). Manney

Correspondence to: A. Kleinböhl

(armin.kleinboehl@jpl.nasa.gov) et al. (1994) described the evolution of the Arctic vortex during two stratospheric warmings in 1993 in which wave 1 was dominant, leading to a displacement of the vortex from the pole. It was shown that low-latitude air was drawn to high latitudes into the developing anticyclone. Further work showed that these events could lead to the formation of low ozone pockets in the middle stratosphere at pressure levels between 5 and $15 \mathrm{hPa}$ (Manney et al., 1995). These low ozone pockets were located inside the anticyclone and revealed ozone mixing ratios comparable to inner vortex values. Morris et al. (1998) showed that the underlying mechanism of these low ozone pockets was the confinement of the airmasses at high latitudes long enough (in the order of weeks), such that ozone loss towards the photochemical equilibrium could occur. Variability of mid-stratospheric ozone related to planetary wave activity was also studied using ground-based observations in the Arctic (Sinnhuber et al., 1999) and at midlatitudes (Calisesi et al., 2001).

In the following we report measurements of unusually high mixing ratios of $\mathrm{N}_{2} \mathrm{O}$ and ozone in the Arctic middle stratosphere by the airborne submillimeter radiometer ASUR during a major stratospheric warming in January 2003 that was dominated by wave 2 and lead to a split of the polar vortex. The measurements are compared with measurements in the tropics by the same instrument, to determine the origin of these airmasses, and trajectory calculation will be performed to estimate a timescale for this transport to the Arctic. The estimated timescale will be checked for consistency using calculations with a simple ozone chemistry model along trajectories. Eventually the development of the meteorological situation is studied with a focus on the formation of low ozone pockets.

(C) 2005 Author(s). This work is licensed under a Creative Commons License. 


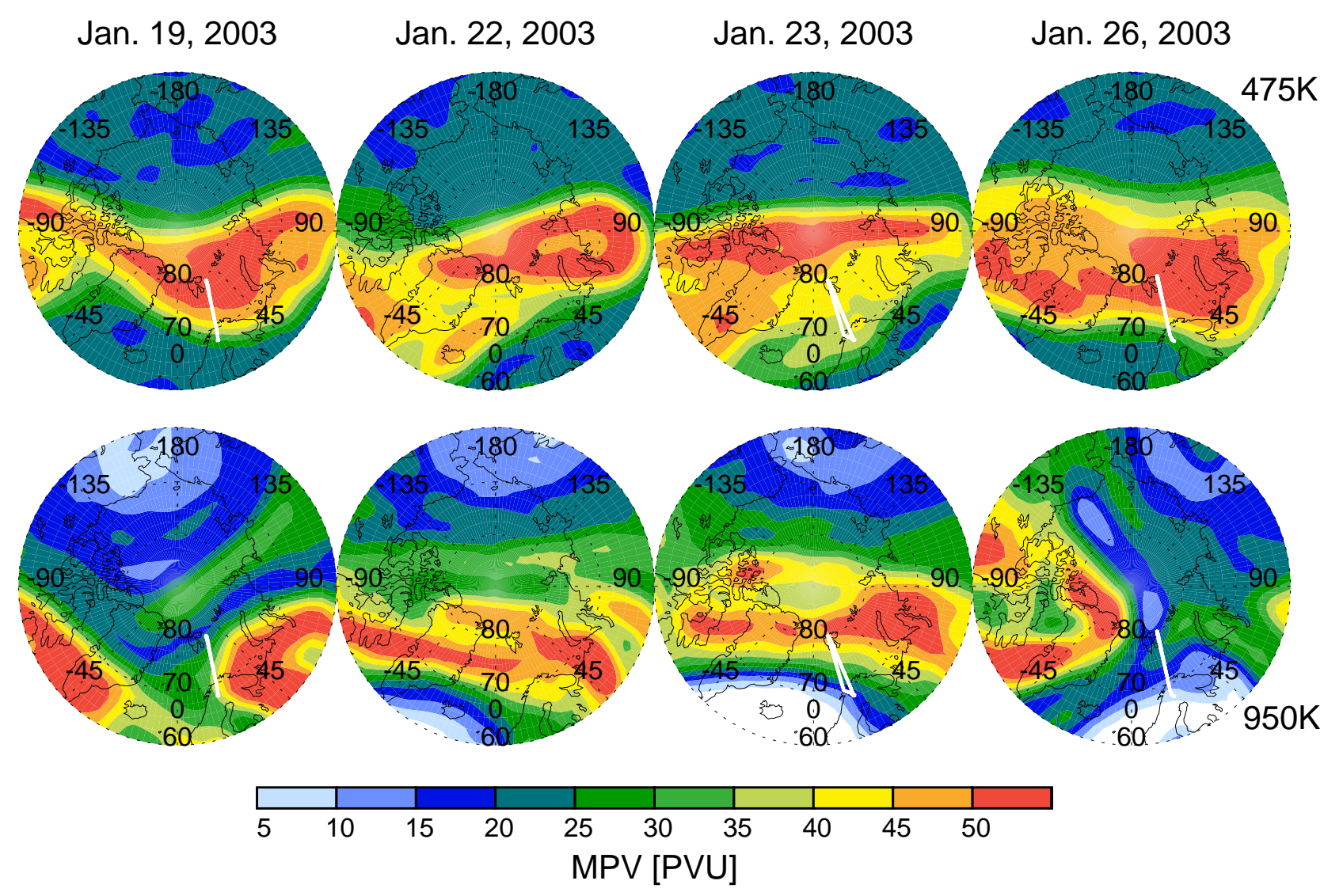

Fig. 1. Maps of modified potential vorticity at a potential temperature of $475 \mathrm{~K}$ ( $\sim 19 \mathrm{~km}$, top) and $950 \mathrm{~K}$ ( $\sim 33 \mathrm{~km}$, bottom) on $19 \mathrm{January}$, 22 January, 23 January, and 26 January 2003 derived from analyses by the European Centre for Medium range Weather Forecast (ECMWF). The reference level for the modified PV is $475 \mathrm{~K}$. The thick white lines indicate the flight paths of the Falcon aircraft on the days where flights were performed.

\section{The ASUR instrument}

Measurements of $\mathrm{N}_{2} \mathrm{O}$ and ozone were performed by the Airborne SUbmillimeter Radiometer ASUR (von König et al., 2000). ASUR is a passive heterodyne radiometer. It uses a liquid helium cooled SIS (superconductor-insulatorsuperconductor) detector (Mees et al., 1995) and operates in single sideband mode, covering a frequency range from 604.3 to $662.3 \mathrm{GHz}$ in which continuous tuning is possible. For spectral analysis of the signals, an acousto-optical spectrometer (AOS) with a band width of $1.5 \mathrm{GHz}$ and a resolution of $1.5 \mathrm{MHz}$ is used (Rosolen et al., 1994). The ASUR instrument is designed to operate on board an aircraft flying near the tropopause to avoid signal absorption due to tropospheric water vapor.

The pressure broadening of the detected emission lines allows the retrieval of vertical profiles of volume mixing ratio (VMR) of the measured species in an altitude range of about 15 to $50 \mathrm{~km}$, with a typical vertical resolution of 6$8 \mathrm{~km}$ in the lower stratosphere, increasing to about $12-15 \mathrm{~km}$ in the middle and upper stratosphere (Bremer et al., 2002).
To achieve a sufficient signal-to-noise ratio, the individually measured spectra are integrated over a time span of about $100 \mathrm{~s}$ in the case of ozone, and about $150 \mathrm{~s}$ in the case of $\mathrm{N}_{2} \mathrm{O}$. These time spans include calibration measurements and correspond to horizontal distances of about 20 and $30 \mathrm{~km}$ at typical aircraft speeds. The retrieval is based on the optimal estimation method (Rodgers, 1976, 1990) and was described in more detail in Bremer et al. (2002).

During winter and spring 2003 the ASUR instrument was deployed on board of the German research aircraft FALCON. In the framework of the European polar stratospheric cloud and lee wave experiment (EUPLEX) nine research flights were undertaken in the Arctic between 14 January and 12 February 2003. During the Sciamachy validation and utilization experiment (SCIA-VALUE) measurements in the tropics were performed between 19 February and 3 March 2003, followed again by measurements in the Arctic between 10 and 19 March 2003. ASUR was looking to the starboard side of the aircraft with a constant elevation angle of $12^{\circ}$. 

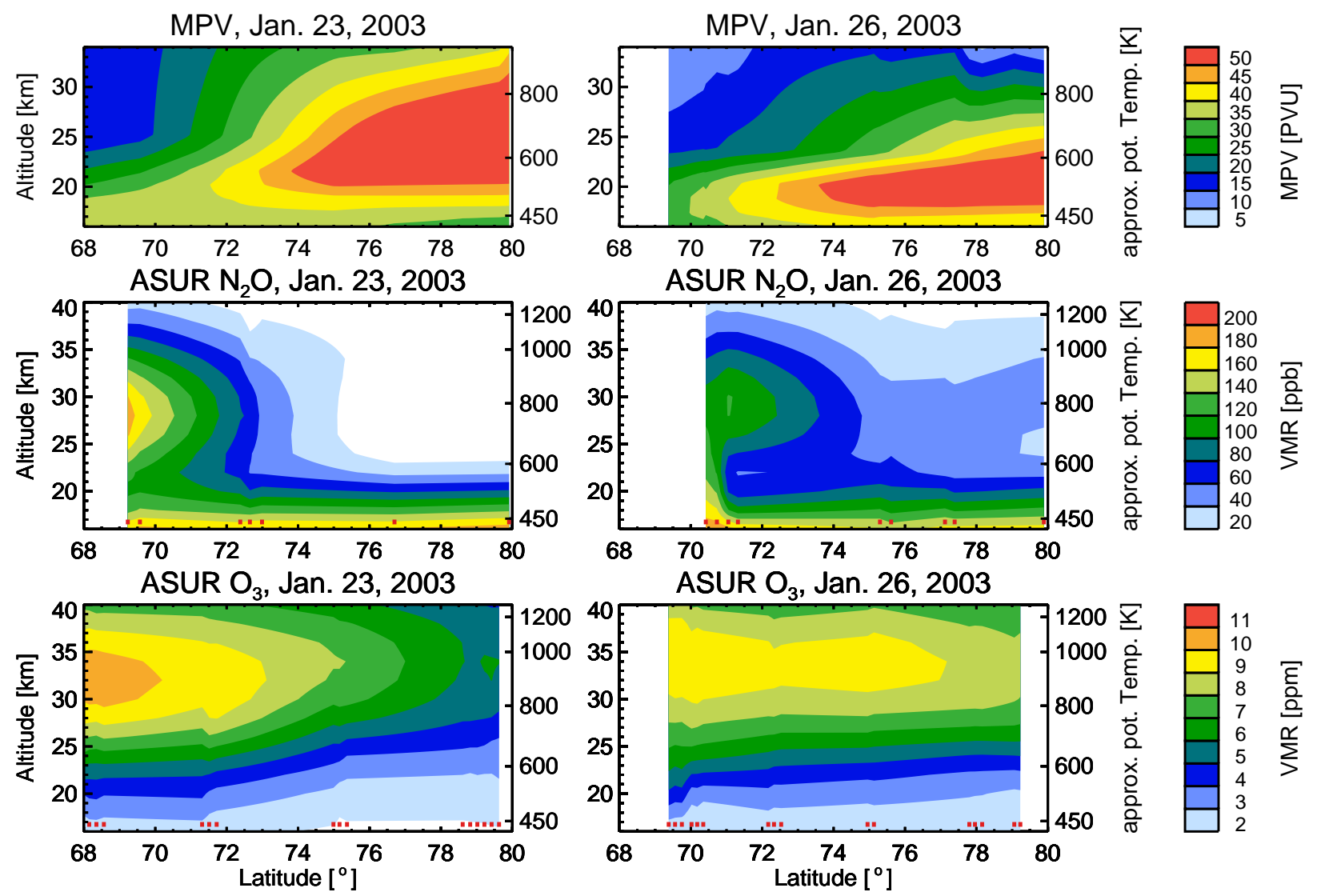

$\frac{\text { 틍 }}{\stackrel{ }{ }}$

Fig. 2. Left: Modified PV from ECMWF analyses along the line of sight of the ASUR instrument (top), ASUR measurements of $\mathrm{N}_{2} \mathrm{O}$ (middle), and ASUR ozone measurements (bottom) during the flight on 23 January 2003 on the flight leg from Spitsbergen to Kiruna. Right: ECMWF MPV, ASUR $\mathrm{N}_{2} \mathrm{O}$, and ASUR ozone during the flight on 26 January 2003. The small red tick marks on the bottom of the measurement contour plots indicate the position of the individual measurements.

\section{Observations}

\subsection{Meteorological situation}

The vortex situation in the Arctic winter 2002/2003 was characterized by very low temperatures and a very strong vortex already in late November 2002. The low temperatures persisted until the end of December when a minor warming in the upper stratosphere occurred. In the lower stratosphere, however, the temperature distribution was hardly disturbed and the vortex remained strong and stable (EORCU, 2003).

This situation changed around mid-January 2003 when a major stratospheric warming took place in the Arctic. The criteria for a major warming, a positive temperature gradient between $60^{\circ} \mathrm{N}$ and the pole together with a reversal of the mean zonal winds at $60^{\circ} \mathrm{N}$ at a pressure level of $10 \mathrm{hPa}$ ( $\sim 825 \mathrm{~K}$ potential temperature) from westerly to easterly were fulfilled on 18 January 2003 (EORCU, 2003). Figure 1 shows maps of the modified potential vorticity (MPV) at the potential temperature levels of $475 \mathrm{~K}(\sim 19 \mathrm{~km})$ and $950 \mathrm{~K}$ $(\sim 33 \mathrm{~km})$ for four days between 19 and 26 January 2003.
MPV is a concept of potential vorticity in which the exponential variation with altitude, as found in the formulation of Ertel's potential vorticity, is removed (Lait, 1994). It can be clearly seen that the warming was accompanied by strong planetary wave 2 activity that led to a split of the vortex on 19 January 2003. The vortex was strongly sheared with altitude. At $950 \mathrm{~K}$ the airmasses above Kiruna had higher PV than the airmasses close to Spitsbergen. On 22 January 2003 the two vortex parts had re-merged on both potential temperature levels. At $950 \mathrm{~K}$ airmasses with high PV had moved northwards and air with very low MPV values $(<5 \mathrm{PVU})$ had moved to the North Atlantic region, reaching $70^{\circ} \mathrm{N}$ on 23 January 2003. On 26 January 2003 the vortex had split again on the $950 \mathrm{~K}$ level and airmasses with an MPV around 10-15 PVU had moved further northwards over Spitsbergen and across the pole.

\subsection{Arctic observations}

The FALCON with the ASUR instrument undertook flights from Kiruna to Spitsbergen and back to Kiruna on 19, 23, and 

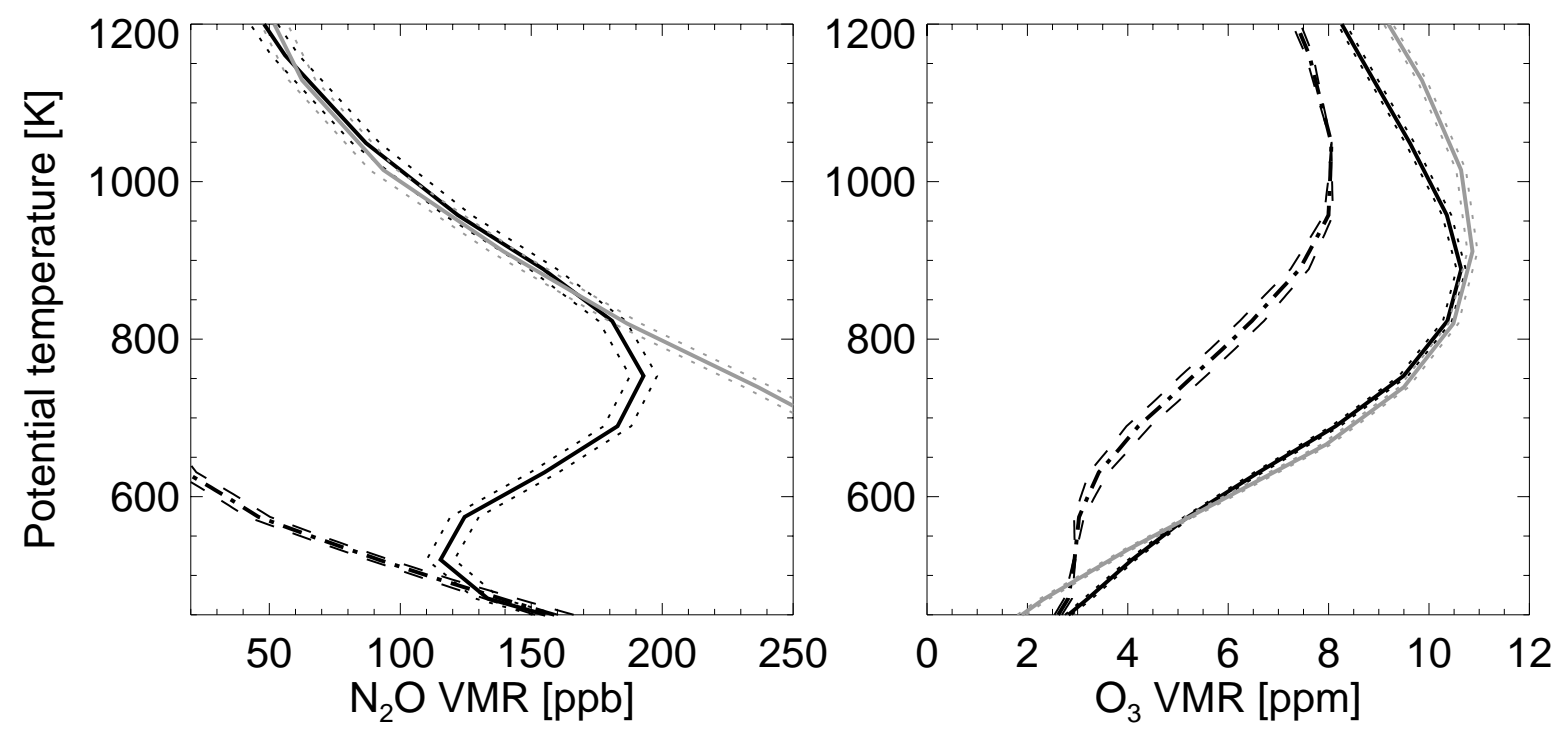

Fig. 3. Black dash-dotted lines: ASUR $\mathrm{N}_{2} \mathrm{O}$ profile (left) and $\mathrm{O}_{3}$ profile (right) of averaged ASUR measurements on 19 January 2003 inside the vortex using a vortex edge at $475 \mathrm{~K}$. The dashed lines represent the standard deviation. Black solid lines: ASUR $\mathrm{N}_{2} \mathrm{O}$ measurement at $69.2^{\circ} \mathrm{N}, 20.2^{\circ} \mathrm{E}$ (left) and ASUR $\mathrm{O}_{3}$ measurement at $68.6^{\circ} \mathrm{N}, 20.3^{\circ} \mathrm{E}$ (right) on 23 January 2003. The dotted lines represent the statistical error derived from the measurement noise. Gray lines: ASUR $\mathrm{N}_{2} \mathrm{O}$ measurement at $17.5^{\circ} \mathrm{N}, 8.1^{\circ} \mathrm{E}$ (left) and ASUR $\mathrm{O}_{3}$ measurement at $20^{\circ} \mathrm{N}, 8.8^{\circ} \mathrm{E}$ (right) on 1 March 2003. The dotted lines represent the statistical error derived from the measurement noise.

26 January 2003. The flight tracks are shown in the maps in Fig. 1.

Figure 2 shows a latitudinal cross section of the ASUR $\mathrm{N}_{2} \mathrm{O}$ measurements on 23 January 2003 during the flight leg from Spitsbergen to Kiruna. The latitudinal variation up to about $20 \mathrm{~km}$ altitude is small, the $\mathrm{N}_{2} \mathrm{O}$ mixing ratios are typical for Arctic vortex profiles after significant descent of the airmasses. Between $76^{\circ} \mathrm{N}$ and $73^{\circ} \mathrm{N}$ a strong increase of $\mathrm{N}_{2} \mathrm{O}$ with decreasing latitude starts to occur, and $\mathrm{N}_{2} \mathrm{O}$ values of almost $200 \mathrm{ppb}$ are reached at altitudes between 25 and $30 \mathrm{~km}$ around $69^{\circ} \mathrm{N}$. This behavior is qualitatively correlated with a decrease in the MPV of the airmasses at these altitudes, which decreases from about 50 PVU to about 15 PVU during this flight leg.

Figure 2 also shows the latitudinal cross section of the ASUR $\mathrm{O}_{3}$ measurements during the same flight leg. Peak mixing ratios between 5 and $6 \mathrm{ppm}$ at around $80^{\circ} \mathrm{N}$ increase with decreasing latitude to values above $10 \mathrm{ppm}$ around $68^{\circ} \mathrm{N}$.

A similar information is shown in Fig. 2 for the flight on 26 January 2003. Again high $\mathrm{N}_{2} \mathrm{O}$ mixing ratios in the middle stratosphere are qualitatively correlated with low values of MPV, though the $\mathrm{N}_{2} \mathrm{O}$ mixing ratios reach only $\sim 140 \mathrm{ppb}$ in the maximum. Airmasses with $\mathrm{N}_{2} \mathrm{O}$ mixing ratios around $80 \mathrm{ppb}$ had moved to the region around $80^{\circ} \mathrm{N}$. The ozone observed in the middle stratosphere is more homogeneous compared to the flight from 23 January 2003, with maximum mixing ratios around $8-9 \mathrm{ppm}$.

The profile with the maximum peak value in $\mathrm{N}_{2} \mathrm{O}$ on the flight from 23 January 2003 is shown in detail in the left part of Fig. 3 on a potential temperature scale. The lowermost part of the profile is determined by a decrease in $\mathrm{N}_{2} \mathrm{O}$, as it can be expected in the Arctic stratosphere at these altitudes. For comparison an averaged profile of measurements inside the vortex at a potential temperature of $475 \mathrm{~K}$ from the flight on 19 January 2003 is also shown. Up to a potential temperature level of about $500 \mathrm{~K}(\sim 20 \mathrm{~km})$ the profiles are basically identical. Above this level the $\mathrm{N}_{2} \mathrm{O}$ mixing ratio in the profile from 23 January 2003 starts to rise, peaking at about $750 \mathrm{~K}$ $(\sim 28 \mathrm{~km}$ ) with a mixing ratio of $193 \mathrm{ppb}$. Above this peak the mixing ratio decreases again.

The ozone measurement closest to the $\mathrm{N}_{2} \mathrm{O}$ profile from 23 January 2003 was located at $68.6^{\circ} \mathrm{N}$. It is shown in the right part of Fig. 3, together with an average of measurements inside the vortex at a potential temperature of $475 \mathrm{~K}$ on 19 January 2003. Around $450 \mathrm{~K}$ the ozone profile from 23 January 2003 is identical with the average from 19 January 2003. Above this altitude the profile from 23 January 2003 exceeds the profile from 19 January 2003 and reaches its maximum of about $10.5 \mathrm{ppm}$ around $900 \mathrm{~K}$.

\subsection{Comparison with tropical measurements}

To study the origin of these unusual $\mathrm{N}_{2} \mathrm{O}$ mixing ratios in the Arctic, the profile has been compared with measurements obtained during flights of the second phase of the SCIAVALUE campaign, which took place between mid-February and mid-March 2003 (Fix et al., 2005). During this campaign latitudinal cross sections ranging from about $80^{\circ} \mathrm{N}$ in the Arctic to about $5^{\circ} \mathrm{S}$ in the tropics were flown. A profile 
which is very similar to the upper part of the Arctic profile from 23 January 2003 was found on a flight on 1 March 2003 from Douala, Cameroon to Tozeur, Tunisia, at $17.5^{\circ} \mathrm{N}$. Figure 3 shows this profile in comparison with the Arctic profile. The agreement between $800 \mathrm{~K}(\sim 29 \mathrm{~km})$ and $1200 \mathrm{~K}$ $(\sim 39 \mathrm{~km})$ is striking, considering that these two measurements were separated by more than $50^{\circ}$ in latitude.

The very good agreement between the $\mathrm{N}_{2} \mathrm{O}$ measurement in the tropics and the Arctic measurement on 23 January 2003 above $800 \mathrm{~K}$ suggests that the origin of these airmasses was in the tropics, and that they were transported to the Arctic by meridional transport. Due to the very good agreement between the Arctic $\mathrm{N}_{2} \mathrm{O}$ profile measured on 23 January 2003 and the tropical $\mathrm{N}_{2} \mathrm{O}$ profile we conclude that this transport did not deviate strongly from isentropic transport. This is plausible as the timescales for the transport are only in the order of days and the net cooling rate in the middle stratosphere at mid-latitudes is in the order of $1 \mathrm{~K} / \mathrm{d}$ in winter (Andrews et al., 1987). It is noted that due to the altitude resolution of the ASUR measurement tropical airmasses down to an altitude around $25 \mathrm{~km}(\sim 650 \mathrm{~K})$ would be required to result in a peak structure as observed, assuming that the retrieved ASUR profile in the tropics reflects the shape of the true tropical profile sufficiently well. However, it is possible that the shape of the profile below about $800 \mathrm{~K}$ could also be caused by contributions of airmasses transported from regions in mid-latitudes.

To study the variation in ozone the profile next to the tropical measurement of $\mathrm{N}_{2} \mathrm{O}$ was considered. It was located at $20^{\circ} \mathrm{N}$ and is shown in Fig. 3. Above $550 \mathrm{~K}$ the profile from 23 January 2003 is very similar to the tropical ozone profile measured on 1 March 2003. Above about $900 \mathrm{~K}$ the two profiles start to deviate from each other, and at $1200 \mathrm{~K}$ the tropical profile exceeds the Arctic profile by about $1 \mathrm{ppm}$. As the lifetime of ozone is in the order of days around $40 \mathrm{~km}$ and in the order of weeks around $30 \mathrm{~km}$ altitude (e.g. Brasseur and Solomon, 1986), the similarity of the Arctic and tropical $\mathrm{O}_{3}$ profiles leads to the conclusion, that the quasi-isentropic transport must have occurred rather rapidly to preserve most of the ozone between 30 and $40 \mathrm{~km}$.

\section{Model calculations}

\subsection{Trajectory calculations}

To study the origin of the airmasses observed in the Arctic on 23 January 2003 calculations of back trajectories were performed using the model described by Schoeberl and Sparling (1994). The trajectories were calculated on five different potential temperature levels and started along the field of view of the ASUR ozone measurement at $68.6^{\circ} \mathrm{N}, 20.3^{\circ} \mathrm{E}$ on 23 January 2003. For comparison trajectories were also calculated from locations $0.5^{\circ}$ north and south as well as $1.5^{\circ}$ east and west of the field of view of the measurement. The

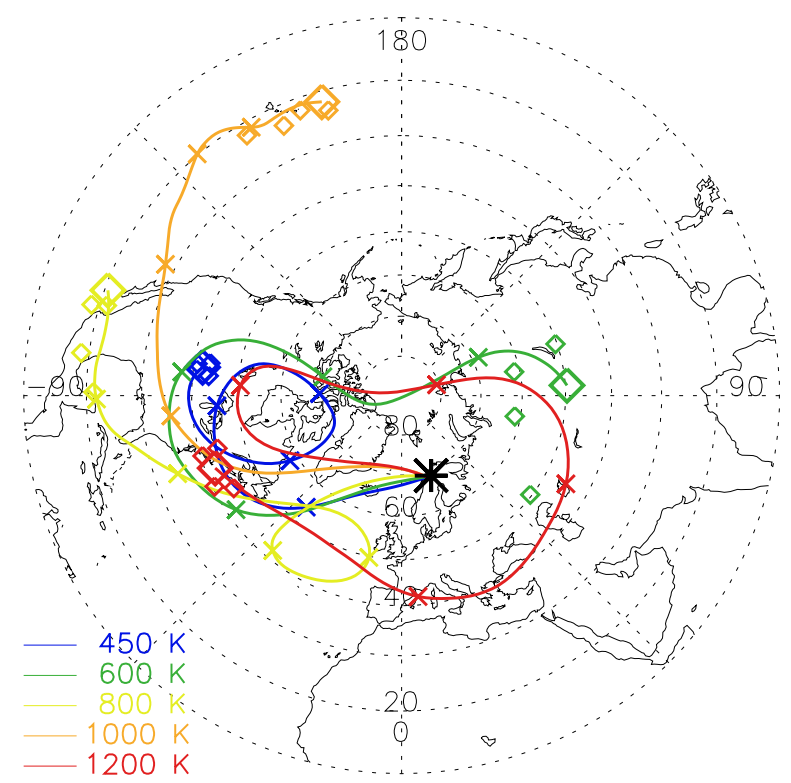

Fig. 4. Backward trajectories calculated from meteorological data by the Goddard Data Assimilation Office. The trajectories were started on 23 January 2003 along the line of sight of the ASUR measurement at $68.6^{\circ} \mathrm{N}, 20.3^{\circ} \mathrm{E}$ at potential temperatures of $450 \mathrm{~K}$ (blue), $600 \mathrm{~K}$ (green), $800 \mathrm{~K}$ (yellow), $1000 \mathrm{~K}$ (orange), $1200 \mathrm{~K}$ (red). The crosses mark the air parcel positions in intervals of one day. The large diamonds show the air parcel positions after five days while the small diamonds indicate the 5-day positions of air parcels initialized $0.5^{\circ}$ north or south, or $1.5^{\circ}$ east or west of the measurement.

trajectories were calculated using meteorological data by the Goddard Data Assimilation Office.

Figure 4 shows the calculated back trajectories over five days. It can be seen that the airmasses at $450 \mathrm{~K}$ potential temperature originate in the vortex region, as expected from the observed $\mathrm{N}_{2} \mathrm{O}$ volume mixing ratios. This is supported by a comparison to the potential vorticity maps in Fig. 1 which show an elongated vortex stretching over Greenland to North-eastern Canada. It is further shown that the different initialized airparcels stay in close proximity to each other. At $600 \mathrm{~K}$ the trajectory shows that the airmasses had been moving around the Arctic in proximity of the vortex and were located over Asia around $50-60^{\circ}$ latitude five days before the measurement. It has to be noted that the trajectories of the different airparcels initialized close to the measurement at this potential temperature level had started to diverge after five days of backward calculation. Calculating further leads some trajectories back towards the pole again, others farther south to regions around $30-40^{\circ}$ latitude after two more days (not shown).

The trajectories at 800 and $1000 \mathrm{~K}$ show that the airmasses at these altitudes originated in the tropics at about $20^{\circ}$ latitude. The $1000 \mathrm{~K}$ trajectory had reached this latitude after 

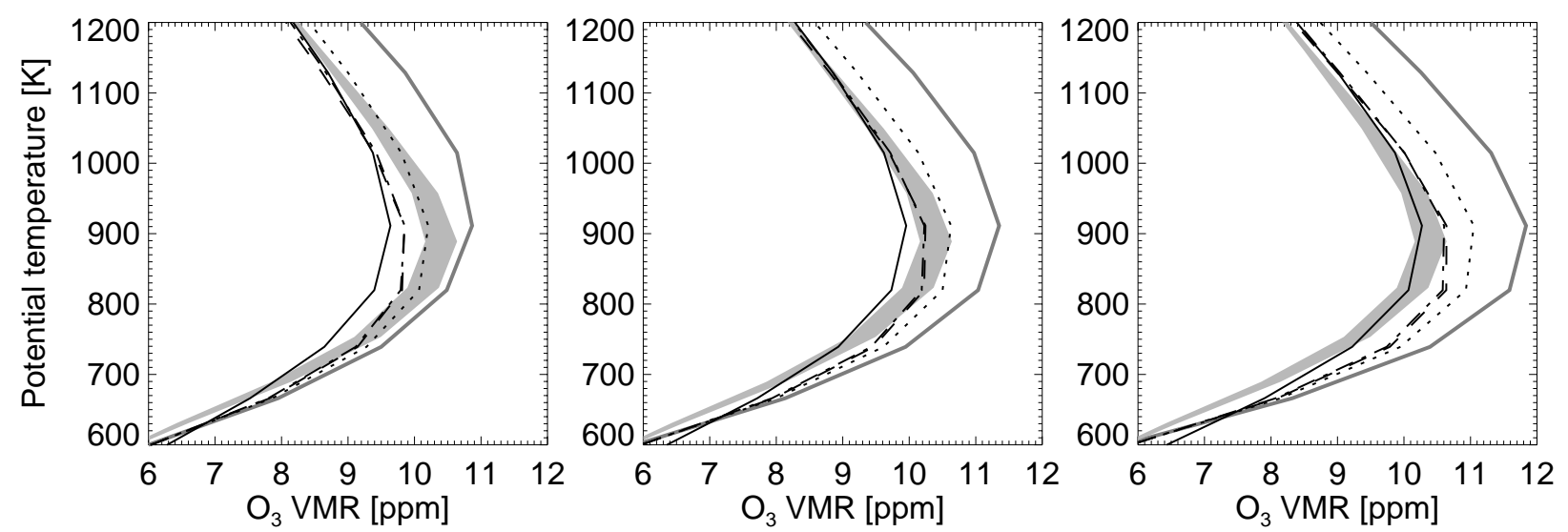

Fig. 5. Model calculations of ozone mixing ratios after transport along trajectories assuming different initial profiles (dark gray lines, left: ozone profile measured at $20^{\circ} \mathrm{N}$; right: ozone profile measured at $15^{\circ} \mathrm{N}$; middle: ozone profile interpolated to $17.5^{\circ} \mathrm{N}$ ). Black dotted lines: resulting profile assuming a transport on idealized trajectories in 3 days. Black dashed lines: resulting profile assuming a transport on idealized trajectories in 5 days. Black dash-dotted lines: resulting profile for transport on calculated trajectories (comp. Fig. 4). Black solid lines: resulting profile for transport on calculated trajectories, assuming an initial profile measured at $46^{\circ} \mathrm{N}$ below 700 and above $1100 \mathrm{~K}$. The light gray shaded area indicates the expected ozone derived from the measurements on 23 January 2003.

calculating three days backward, for the $800 \mathrm{~K}$ trajectory it was 4-5 days. Divergence of the different airparcel initializations exists after $4-5$ days but is small in latitudinal direction. In contrast, the trajectory at $1200 \mathrm{~K}$ suggests that the airmasses had circled once around the pole in the five day period considered in Fig. 4, and were located in close proximity to each other between 40 and $50^{\circ}$ latitude.

For comparison calculations were also performed using a different meteorological data set (UKMO). While agreeing in the latitudes of origin of the airmasses, differences between the actual trajectory paths and in the divergence were observed, revealing some uncertainty in the calculation of the actual airmass trajectory in this complicated meteorological situation.

\subsection{Modeling of the ozone change}

To further assess the consistency between the $\mathrm{N}_{2} \mathrm{O}$ and $\mathrm{O}_{3}$ measurements on 23 January 2003 and the suggested airmass origins by the trajectory calculations a simple model of linearized ozone chemistry (LINOZ) (McLinden et al., 2000) is used.

Some care has to be taken concerning the start and end profiles of ozone, as the ozone measurements shown in Fig. 3 were not exactly co-located with the $\mathrm{N}_{2} \mathrm{O}$ measurements, and significant ozone gradients between different measurements exist. In the tropics ozone measurements are available at latitudes of $20^{\circ} \mathrm{N}$ and $15^{\circ} \mathrm{N}$ which will be considered as a lower and upper limit, respectively. Additionally a calculation was performed with an initial profile obtained from an interpolation between these two ozone measurements. In the Arctic the ozone measurement closest to the $\mathrm{N}_{2} \mathrm{O}$ measurement in Fig. 3 is located $0.6^{\circ}$ to the south and will be considered as an upper limit. The closest ozone measurement to the north is significantly farther away, so an interpolation to a location $0.6^{\circ}$ north of the $\mathrm{N}_{2} \mathrm{O}$ measurement seems to be a reasonable estimate for a lower ozone limit.

Model calculations were performed along the trajectories shown in Fig. 4 in a way that the $600 \mathrm{~K}$ trajectory was considered for potential temperatures below $700 \mathrm{~K}$, the $800 \mathrm{~K}$ trajectory between 700 and $900 \mathrm{~K}$, the $1000 \mathrm{~K}$ trajectory between 900 and $1100 \mathrm{~K}$, and the the $1200 \mathrm{~K}$ trajectory above. The calculations were initialized with the measured profiles as described above. To account for mid-latitude origins of the airmasses around 600 and $1200 \mathrm{~K}$, another run was performed with an initial ozone profile measured by ASUR in late-February 2003 around $46^{\circ} \mathrm{N}$ for potential temperature levels below 700 and above $1100 \mathrm{~K}$. Due to some uncertainty of the trajectories in this complicated meteorological situation, model calculations were also performed to simulate transport along idealized trajectories from $20^{\circ} \mathrm{N}$ to $70^{\circ} \mathrm{N}$. Transport times of 3 and 5 days were assumed, respectively. The vertical spacing for the calculations corresponded to $2 \mathrm{~km}$. Figure 5 shows the results of the model calculations using the different initial profiles. The expected ozone mixing ratios around the $\mathrm{N}_{2} \mathrm{O}$ measurement from 23 January 2003 are displayed as shaded areas in light gray. The resulting profiles were convolved to the altitude resolution of the ASUR ozone measurements by using the appropriate averaging kernel functions (Bremer et al., 2002).

Using the lowest initial profile (left plot in Fig. 5) best agreement with the Arctic profile is achieved with the idealized trajectory that transports the airmasses from the tropics to the Arctic in only three days. The transport along the calculated trajectories with the full tropical initial profile as well as along the 5-day idealized trajectory yield ozone mixing 
ratios that are nearly identical. However, with lowest initial profile they are too low at potential temperatures above $850 \mathrm{~K}$. Concerning the initialization with the mid-latitude profile at high and low altitudes, little difference to the initialization with tropical profiles is evident between 1000 and $1200 \mathrm{~K}$. This is caused by the fact that the ozone maximum of the mid-latitude profile, though lower in volume mixing ratio, is located at a higher altitude than the maximum of the tropical profile. This results in very similar ozone mixing ratios around $1100-1200 \mathrm{~K}$ for both profiles. We note that the significant difference between both profiles around $800 \mathrm{~K}$ is caused by the low ozone values of the mid-latitude initial profile around $700 \mathrm{~K}$ which remain nearly unchanged due to the long life time of ozone at these altitudes. The convolution of the model profile with the averaging kernels of the ASUR measurement results in a decrease of ozone VMR also at higher altitudes.

With the intermediate start profile (center plot in Fig. 5) best agreement is achieved with the transport along the calculated trajectory as well as with the 5-day idealized trajectory, which is nearly identical again. The modeled profile agrees well with the Arctic observation in the range from $750 \mathrm{~K}$ up to $1200 \mathrm{~K}$.

The start profile in the upper limit (right plot in Fig. 5) yields too high ozone mixing ratios with three days of transport on an idealized trajectory. Also the modeled ozone along the calculated trajectories shows higher mixing ratios, in particular below $900 \mathrm{~K}$, as does the modeled ozone along the 5day idealized trajectory, which is slightly higher. However, in this scenario the modeled profile with the mid-latitude initialization at low and high altitudes reveals very good agreement between about 700 and $1100 \mathrm{~K}$.

\subsection{Error discussion}

As the initial profiles were derived from ASUR ozone measurements the true initial profiles might deviate from the measured profile shape due to the altitude resolution of the measurement. Sensitivity studies using the climatological ozone mixing ratios of the LINOZ model suggest that the deviations due to altitude resolution should be less than $0.6 \mathrm{ppm}$ below $40 \mathrm{~km}$.

The runs shown in Fig. 5 were performed with climatological temperatures and ozone columns taken from the LINOZ model. To test the sensitivity on the ozone column, runs on idealized trajectories were performed where the ozone column was calculated from the initial profile, and successively from the modeled profile after each time step. The modeled deviations were less than $0.1 \mathrm{ppm}$ below $30 \mathrm{~km}$ and less than $0.25 \mathrm{ppm}$ below $40 \mathrm{~km}$, which do not change the results significantly.

To test the sensitivity on the temperature profiles runs on idealized trajectories with climatological temperatures from the LINOZ model increased by $5 \mathrm{~K}$ and decreased by $10 \mathrm{~K}$ were performed. These values were chosen as they reflect the maximum deviations of the climatological profiles from synoptic temperature profiles from analyses by the Data Assimilation Office (DAO) at the ASUR measurement locations in the tropics and in the Arctic, respectively. The run with increased temperature did not show significant deviations, only with the highest initial ozone profile the results showed a better fit to a transport time of five days on an idealized trajectory. In the run with decreased temperatures the profile shape was less well reproduced. Deviations up to $800 \mathrm{~K}$ potential temperature were negligible, further above the calculated ozone values became higher than with the original temperatures, with a maximum deviation at $1200 \mathrm{~K}$ of $\sim 0.5 \mathrm{ppm}$ in the case of the low initial ozone profile and $\sim 0.8 \mathrm{ppm}$ in the case of the high initial ozone profile.

Another consideration in terms of sensitivity is the accuracy of the ASUR measurements, which is estimated to be $15 \%$. As most of the ozone comparisons with other measurements indicate that ASUR ozone measurements are rather on the high side (Bremer et al., 2002), a test run with ASUR ozone decreased by $15 \%$ was performed. Similar to the run with decreased temperatures the observed profile shape was less well reproduced by the model. Up to a potential temperature of $\sim 900 \mathrm{~K}$ the behavior did not change significantly, above $\sim 1000 \mathrm{~K}$ one would have to assume longer transport times ( $\sim 7-10$ days) to fit the measurements.

Recent work that compared LINOZ simulations to calculations with other linearized ozone schemes formulated doubts about the appropriateness of the LINOZ scheme for upper stratospheric studies (McCormack et al., 2004). While this seems the case for mid-stratospheric airmasses largely confined at high latitudes it is not obvious for the case in which mid-latitude airmasses were transported towards the pole, in particular at timescales of 4-5 days where LINOZ gives very reasonable results (comp. Fig. 11 in McCormack et al. (2004)). As the latter case is the most comparable to the situation studied in this work it seems unlikely that uncertainties or inaccuracies in the LINOZ coefficients should have a larger impact than the other error sources discussed above.

\subsection{Development of the meteorological situation}

To study the development of the situation, maps of modified PV up to 4 February 2003 are considered. The morphology of the situation is of particular interest concerning the formation of low ozone pockets, which can be caused by confinement of airmasses in anticyclones at high latitudes and subsequent ozone destruction towards the photochemical equilibrium.

Already in the map of MPV at $950 \mathrm{~K}$ from 26 January 2003 (Fig. 1) it can be seen that the feature of low PV airmasses moving into the North Atlantic was moving southwards and only a filament was moving northwards over the pole. This leads to a rather homogeneous ozone distribution in the middle stratosphere along the flight track, as observed by ASUR in Fig. 2. 

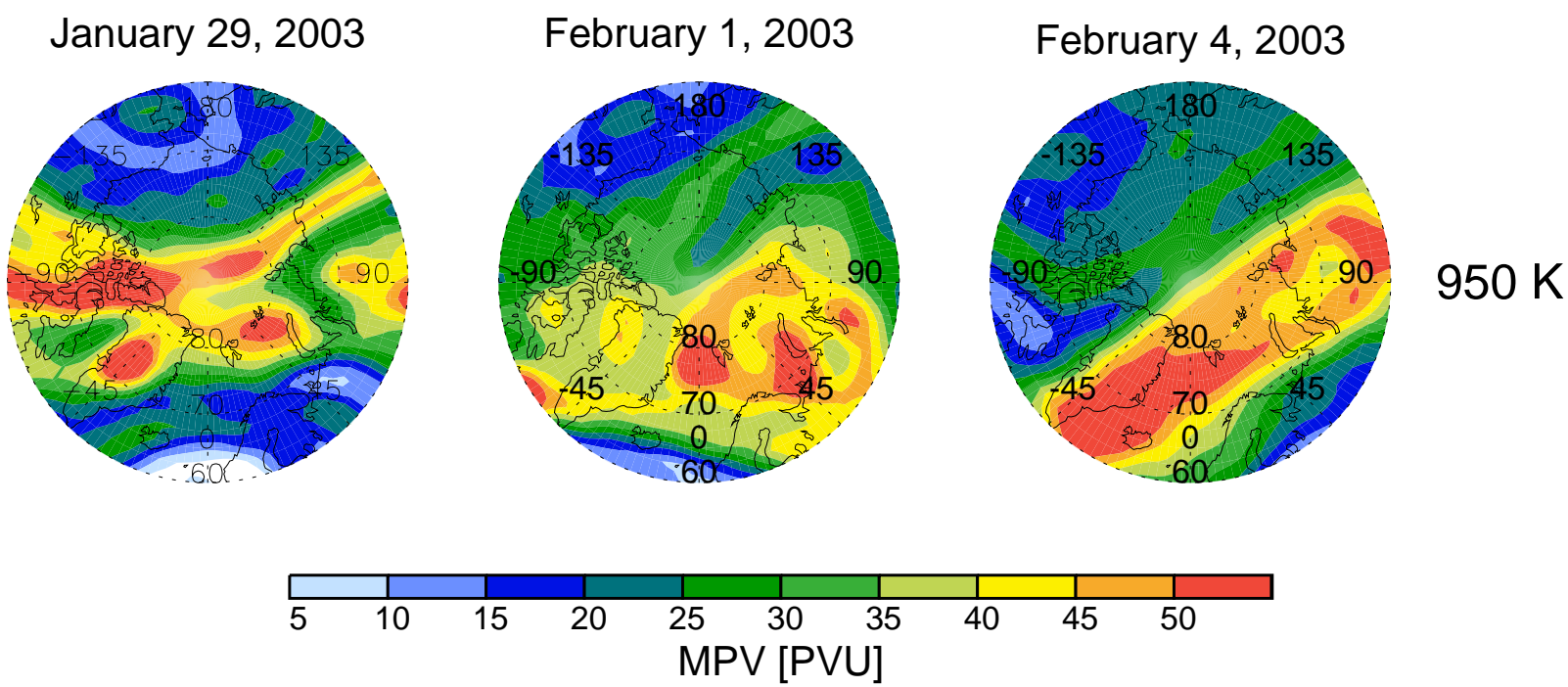

Fig. 6. Maps of modified PV for 29 January, and 1, 4 February 2003 at a potential temperature level of $950 \mathrm{~K}$ from ECMWF analyses. The reference level for the modified PV is $475 \mathrm{~K}$.

Figure 6 shows that by 29 January the area with low PV has moved further south again and on 1 February no airmasses with PV lower than 15 PVU are found over Scandinavia north of $60^{\circ}$ N. Similarly, the anticyclone over Alaska and Eastern Siberia, well developed around 19 and 23 January, gets disturbed by 26 January and moves eastwards and southwards around 1 February, such that only little air with PV lower than 15 PVU is found north of $60^{\circ} \mathrm{N}$ by 4 February 2003.

It can be concluded that the confinement of airmasses at polar latitudes which is necessary for the formation of low ozone pockets was not realized after the stratospheric warming in mid-January 2003, likely related to the planetary wave 2 activity present, and the resulting movement of airmasses between Arctic and mid-latitude regions.

\section{Conclusions}

During the wave 2 dominated major stratospheric warming in January 2003 in the Arctic unusually high mixing ratios of ozone and $\mathrm{N}_{2} \mathrm{O}$ were observed by ASUR in the middle stratosphere $(\sim 25-40 \mathrm{~km})$. The maximum $\mathrm{N}_{2} \mathrm{O}$ mixing ratios observed during a flight between $68^{\circ}$ and $80^{\circ} \mathrm{N}$ on 23 January 2003 in the Arctic were nearly identical to mixing ratios measured around $20^{\circ} \mathrm{N}$ on 1 March 2003 above about $800 \mathrm{~K}$ potential temperature. The observed ozone values corresponding to these $\mathrm{N}_{2} \mathrm{O}$ measurements in the Arctic were very similar to their tropical counterparts between 600 and $900 \mathrm{~K}$, and started to decrease slowly above. In the lower stratosphere $(\sim 20 \mathrm{~km})$ the values of $\mathrm{N}_{2} \mathrm{O}$ and ozone remained typical for Arctic conditions.

From the very good agreement between the $\mathrm{N}_{2} \mathrm{O}$ mixing ratios observed in the Arctic and in the tropics between 800 and $1200 \mathrm{~K}(\sim 29-39 \mathrm{~km})$ it can be concluded that the airmasses must have been transported from the tropics to the Arctic by rapid quasi-isentropic transport. To reproduce the observed structure in $\mathrm{N}_{2} \mathrm{O}$ transport from lower latitudes had to occur on isentropic levels down to about $650 \mathrm{~K}(\sim 25 \mathrm{~km})$.

Calculations of 5-day back trajectories from the Arctic measurements at $68.6^{\circ} \mathrm{N}, 20.3^{\circ} \mathrm{E}$ on 23 January 2003 indicate that in a potential temperature range between about 800 and $1000 \mathrm{~K}$ the airmasses indeed had been drawn from a latitude of about $20^{\circ} \mathrm{N}$ into the Arctic on a timescale of 3-5 days. At levels of 600 and $1200 \mathrm{~K}$ the trajectories indicate that the airmasses had rather been located at latitudes between $40^{\circ}$ and $50^{\circ} \mathrm{N}$ five days prior to the measurement in the Arctic.

Model studies using a linearized ozone chemistry along the calculated trajectories as well as on a set of idealized trajectories at different altitudes and initialized with ASUR ozone measurements around $20^{\circ} \mathrm{N}$ reveal good agreement with the measured ozone in the Arctic with the suggested transport times of 3-5 days. When a mid-latitude origin for the airmasses below $700 \mathrm{~K}$ and above $1100 \mathrm{~K}$ is assumed, the calculations still give reasonable agreement if the highest of the available tropical ozone profiles is considered for initialization between 700 and $1100 \mathrm{~K}$. It can be concluded that the modeled ozone changes confirm the plausibility of this transport considering the uncertainties of the input parameters to the model and the uncertainties of the trajectories.

PV maps do not suggest that this wave 2 process lead to the formation of low ozone pockets, in contrast to earlier work by Manney et al. (1995) which dealt with wave 1 dominated stratospheric warmings, as the airmasses were not confined long enough at polar latitudes to allow the development of low ozone pockets. 
Acknowledgements. We would like to thank G. Näveke for his assistance prior to the measurement campaigns and the crew of the FALCON aircraft for their support during the campaigns. We are grateful to F. Stroh and the EUPLEX team for the opportunity to participate on board the FALCON during EUPLEX. Thanks also to ECMWF, DAO and UKMO for providing meteorological analyses and in particular to the Goddard Space Flight Center for their trajectory tool. Parts of this work were supported by the German contribution to the ENVISAT validation under contract FKZ 50EE 0022 as part of the ESA proposal A. O. ID 349.

Edited by: U. Platt

\section{References}

Andrews, D. G., Holton, J. R., and Leovy, C. B.: Middle atmospheric dynamics, Academic press, San Diego, 1987.

Brasseur, G. P. and Solomon, S.: Aeronomy of the middle atmosphere, D. Reidel Publishing Company, Dordrecht, 1986.

Bremer, H., von König, M., Kleinböhl, A., Küllmann, H., Künzi, K., Bramstedt, K., Burrows, J. P., Eichmann, K.-U., Weber, M., and Goede, A. P. H.: Ozone depletion observed by the Airborne Submillimeter Radiometer (ASUR) during the Arctic winter 1999/2000, J. Geophys. Res., 107, 8277, doi:10.1029/2001JD000546, 2002.

Calisesi, Y., Wernli, H., and Kämpfer, N.: Midstratospheric ozone variability over bern related to planetary wave activity during the winters 1994-1995 to 1998-1999, J. Geophys. Res., 106, 79037916, 2001

EORCU: The northern hemisphere stratosphere in the 2002/03 winter, Tech. rep., European Ozone Research Coordination Unit, available under http://www.ozone-sec.ch.cam.ac.uk/, 2003.

Fix, A., Ehret, G., Flentje, H., Poberaj, G., Gottwald, M., Finkenzeller, H., Bremer, H., Bruns, M., Burrows, J. P., Kleinböhl, A., Küllmann, H., Kuttippurath, J., Richter, A., Wang, P., Heue, K.P., Platt, U., Pundt, I., and Wagner, T., SCIAMACHY validation by aircraft remote sensing: design, execution, and first measurement results of the SCIA-VALUE mission, Atmos. Chem. Phys., 5, 1273-1289, 2005,

SRef-ID: 1680-7324/acp/2005-5-1273.

Lait, L. R.: An alternative form for potential vorticity, J. Atmos. Sci., 15, 1754-1759, 1994

Manney, G. L., Zurek, R. W., O’Neill, A., Swinbank, R., Kumer, J. B., Mergenthaler, J. L., and Roche, A. E.: Stratospheric warmings during february and march 1993, Geophys. Res. Lett., 21, 813-816, 1994.

Manney, G. L., Froidevaux, L., Waters, J. W., Zurek, R. W., Gille, J. C., Kumer, J. B., Mergenthaler, J. L., Roche, A. E., O'Neill, A., and Swinbank, R.: Formation of low-ozone pockets in the middle stratospheric anticyclone during winter, J. Geophys. Res., 100, 13 939-13 950, 1995.
McCormack, J. P., Eckermann, S. D., Coy, L., Allen, D. R., Kim, Y.L., Hogan, T., Lawrence, B., Stephens, A., Browell, E. V., Burris, J., McGee, T., and Trepte, C. R.: NOGAPS-ALPHA model simulations of stratospheric ozone during the SOLVE 2 campaign, Atmos. Chem. Phys., 4, 2401-2423, 2004,

SRef-ID: 1680-7324/acp/2004-4-2401.

McLinden, C. A., Olson, S. C., Hannegan, B., Wild, O., Prather, M. J., and Sundet, J.: Stratospheric ozone in 3-D models: A simple chemistry and the cross-tropopause flux, J. Geophys. Res. 105, 14 653-14 665, 2000.

Mees, J., Crewell, S., Nett, H., de Lange, G., van den Stadt, H., Kuipers, J. J., and Panhuyzen, R. A.: ASUR - an airborne SIS receiver for atmospheric measurements of trace gases at 625 to 760 GHz, IEEE Trans. Microwave Theory Tech., 43, 2543-2548, 1995.

Morris, G. A., Kawa, S. R., Douglas, R. A., Schoeberl, M. R., Froidevaux, L., and Waters, J.: Low-ozone pockets explained, J. Geophys. Res., 103, 3599-3610, 1998.

Rodgers, C. D.: Retrieval of atmospheric temperature and composition from remote measurements of thermal radiation, Rev. Geophys. Space Phys., 14, 609-624, 1976.

Rodgers, C. D.: Characterization and error analysis of profile retrieval from remote sounding measurements, J. Geophys. Res., 95, 5587-5595, 1990.

Rosolen, C., Dierich, P., Michet, D., Lecacheaux, A., Palacin, F., Robiliard, R., Rigeaud, F., and Vola, P.: Wideband acousto optical spectrometer, Final report on workpackage 2411, submillimeter limb sounder breadboarding, ESA, 1994.

Schoeberl, M. R. and Sparling, L. C.: Trajectory modeling, in: Diagnostic tools in atmospheric physics, Proc. S.I.F. Course CXVI, edited by: Fiocco, G. and Visconti, G., North-Holland, Amsterdam, 1994.

Sinnhuber, B.-M., Müller, R., Bovensmann, H., Eyring, V., Klein, U., Langer, J., Trentmann, J., Burrows, J. P., and Künzi, K.: Interpretation of mid-stratospheric arctic ozone measurements using a photochemical box-model, J. Atmos. Chem., 34, 281-290, 1999.

Sinnhuber, B.-M., Weber, M., Amankwah, A., and Burrows, J. P.: Total ozone during the unusual antarctic winter of 2002, Geophys. Res. Lett., 30, 1580, doi:10.1029/2002GL016798, 2003.

von König, M., Bremer, H., Eyring, V., Goede, A., Hetzheim, H., Kleipool, Q., Küllmann, H., and Künzi, K.: An airborne submm radiometer for the observation of stratospheric trace gases, in: Microwave Radiometry and Remote Sensing of the Earth's Surface and Atmosphere, edited by: Pampaloni, P. and Paloscia, S. VSP Utrecht, 409-415, 2000. 